\title{
Københavns nære og fjerne opland før industrialiseringen
}

\author{
Af Jørgen Mikkelsen
}

Denne artikel tager udgangspunkt $i$, at en by kan have mange slags oplande, afhængig af hvilke aktiviteter man taler om. Med inspiration i tre oplandsbegreber, udviklet af tyske forskere, og af von Thünens klassiske teori om, at en by ideelt set er omgivet af koncentriske produktionszoner sættes der fokus på handelsrelationerne mellem København og hovedstadens opland i tiden fra ca. 1700 til omkring 1850, men med linjer op til midten af 1900-tallet.

\section{Opland - et begreb med mange facetter}

I en antologi om de europæiske hovedstæder og deres oplande i perioden ca. 1500-1800 har den engelske historiker Michael Reed formuleret sig således: "All towns are multi-functional, and each function has its own hinterland". ${ }^{1}$ Med denne korte og præcise formulering har han indfanget byernes mangesidige karakter som udvekslingssteder for varer og andre ydelser og som $\emptyset$ konomiske, administrative og kulturelle knudepunkter i regioner af forskellig størrelse.

Indflydelsessfærens størrelse afhænger dog stærkt af, hvad man taler om. Fx opnår man som regel meget forskellige resultater, hvis man kortlægger de områder, hvorfra en by i 1700-tallet skaffede nye købmænd, håndværkere, daglejere og tjenestefolk, idet de erhvervsdrivende ofte kom fra andre byer, mens størstedelen af de ufaglærte stammede fra det nærmeste opland, hvis beboere jævnligt aflagde besøg i byen for at gøre indkøb. ${ }^{2}$ Dog har hovedstæder og meget driftige byer altid været $\mathrm{i}$ stand til at tiltrække alle slags tilvandrere, også tjenestefolk, fra en meget stor omkreds.

I tysk historisk og geografisk forskning skelner man ofte mellem de tre oplandszoner, "Umland", "Hinterland" og "Einflußbereich", når det handler om tiden før industrialiseringen. ${ }^{3}$ Førstnævnte begreb anvendes om arealet inden for 10-30 kilometers afstand fra en by; det var det område, hvorfra der normalt kom besøgende til byens ugemarkeder (torvehandel). "Hinterland" kunne strække sig 50-60 kilometer ud fra byen; det var den region, der kunne forsyne byen med gæster til dens årsmarkeder, og de fleste af de udenbys købmænd og håndværkere, der slog sig ned i byen, stammede også herfra. Endelig dækkede "Einflußbereich" det område, der var omfattet af byens langdistancehandel. Desuden kunne byer med meget store årsmarkeder også tiltrække sælgere og kunder fra dette område.

\section{Det førindustrielle København med von Thünen-zoner}

Det førindustrielle København er en af de byer, hvor det i høj grad giver mening at anvende det tyske begrebsapparat. Ligesom mange andre hovedstæder oplevede København en massiv vækst mellem ca. 1500 og 1800, og alene fra 1660 til 1800 voksede befolkningstallet fra ca. 40.000 til lidt over 100.000, således at hovedstaden ved folketællingen i 1801 (for Sønderjyllands vedkommende 1803) havde flere indbyggere end alle provinskøbstæder i Danmark til sammen. ${ }^{4}$

Den markante vækst må ses i lyset af den stærke centralisering af statsmagten i disse århundreder og den stærke udbygning af hæren og flåden, som i stor udstrækning blev koncentreret i

København. Dette samt den forøgede hofhusholdning gav anledning til en stor efterspørgsel, som styrkede erhvervslivet i København. Dertil kommer, at den merkantilistiske erhvervspolitik med 
mere eller mindre direkte støtte til forskellige industrier reelt favoriserede København på bekostning af provinsbyerne, om end det var hensigten, at disse virksomheder skulle fungere som en motor for det $\varnothing$ konomiske liv i hele monarkiet.

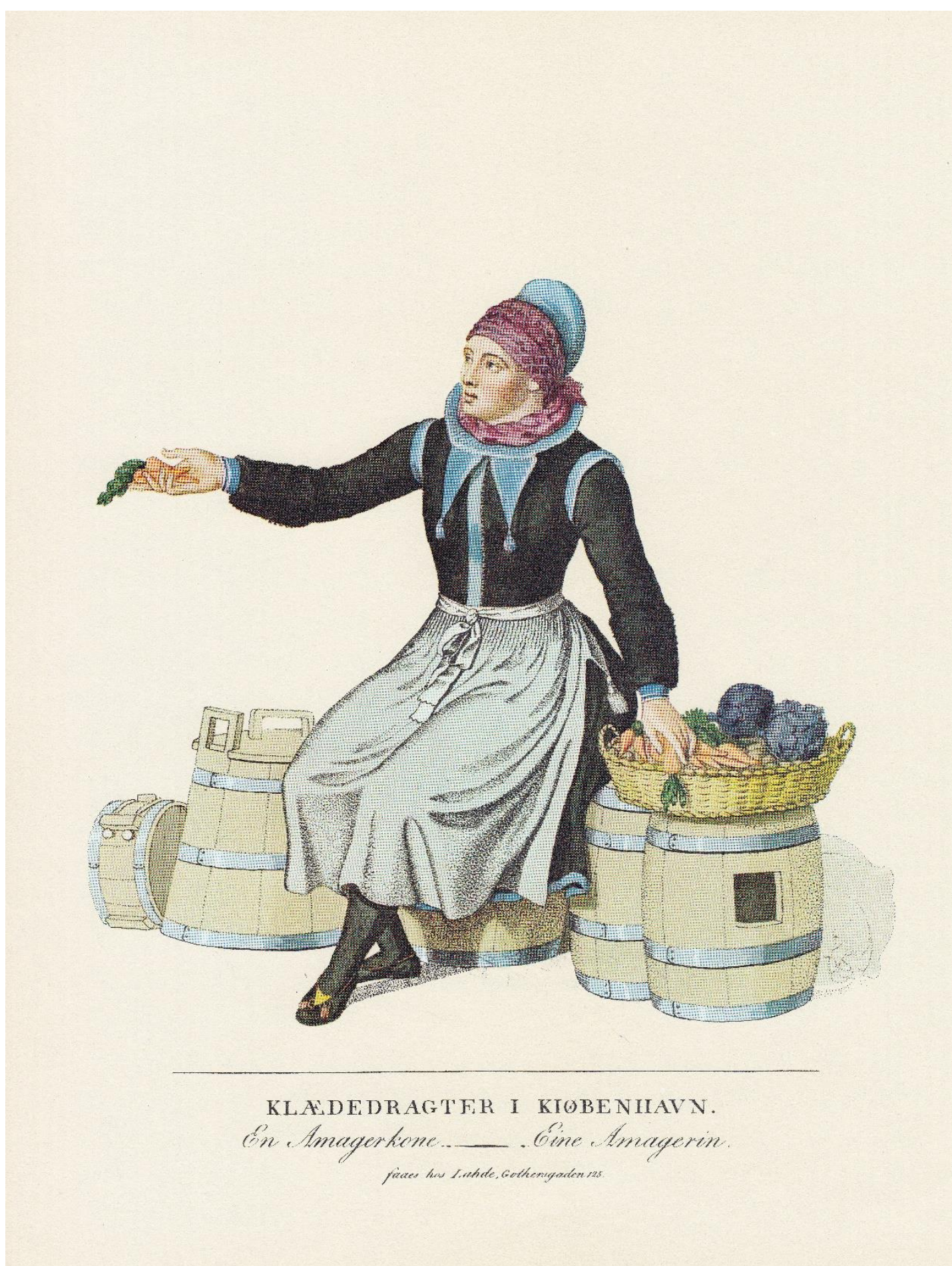

I begyndelsen af 1800-tallet var en lang rekke fine tegninger af persontyper til salg hos hofkobberstikker Gerhard Ludvig Lahde, der boede på adressen Gothersgade 125 i Kobenhavn, hvor malerne Johs. Senn og C.W. Eckersberg arbejdede for ham. Det er uafklaret, hvilke af tegningerne der må tilskrives Lahde, og hvilke der er tegnet af Senn. Blandt tegningerne ses en rakke af de udenbys salgere, der falbød deres varer i København. Bl.a. en Amagerkone. (Kobstadsmuseet Den Gamle By) 
Københavns vækst medførte stigende import af mange slags varer fra de forskellige dele af monarkiet, hvad der var med til at udvide hovedstadens "Einflußbereich". Det drejede sig bl.a. om tømmer og jern fra Norge og brændsel, kød, grønsager og frugt fra forskellige dele af Danmark. Denne varetilførsel var med til at stimulere den indenlandske søfart, som voksede meget i løbet af 1700-tallet. ${ }^{5}$ I dette århundrede var der også en klar vækst i sejladsen på monarkiets besiddelser i Nordatlanten og troperne samt i søfarten på Kina, og også på disse felter havde København en absolut nøglerolle. En betydelig del af de varer, der blev bragt hjem fra kolonierne og Kina, blev dog reeksporteret, men dette gav ofte gode fortjenester til initiativrige borgere i København.

Hovedstadens vækst under enevælden satte også et stærkt præg på Sjælland, hvor man - nok i stadigt stærkere grad - kunne iagttage såkaldte von Thünen-zoner (se Appendix). Fænomenet er opkaldt efter den tyske $\varnothing$ konom Johann Heinrich von Thünen, som i 1826 udarbejdede den teori, at en by vil være omgivet af koncentriske produktionszoner, når der ikke er nogen reel forskel i jordens kvalitet i de enkelte dele af oplandet, idet transportomkostninger da vil bestemme, hvad det er hensigtsmæssigt at dyrke hvert sted.

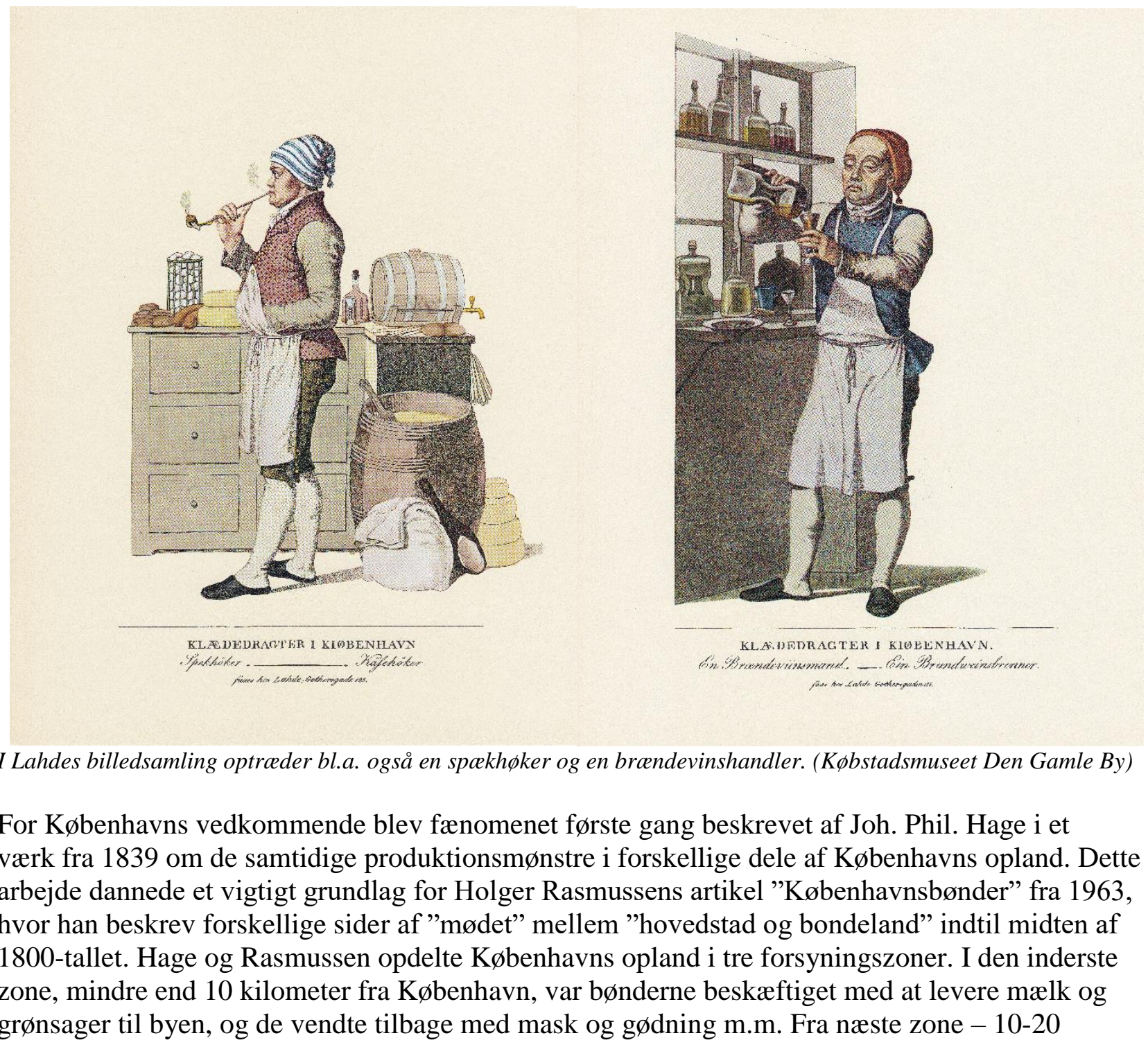


kilometer fra hovedstaden - var hø, halm og kartofler vigtige ydelser, mens korn var det absolutte hovedprodukt fra bønder, der boede på større afstand.

Imidlertid eksisterede der lokale specialiteter inden for hver af zonerne, fortæller Rasmussen og hans hjemmelsmænd, Hage og den samtidige S. Sterm. I nogle tilfælde skyldtes det adgangen til særlige, lokale ressourcer. Det var fx tilfældet med fiskeriet i Skovshoved (hvor Gammel Strand allerede i 1700-tallet fungerede om skovserkonernes salgssted), tørveproduktionen ved Sengeløse og Kirke Værløse og kulsvidningen i skovegnene mod nord (både tørven og kullet blev solgt på Kultorvet).

Derimod kan det umiddelbart være lidt vanskeligt at forstå, hvorfor netop Buddinge var blevet hjemsted for "en hel husindustri med havregrynsmaling", 6 men dette gav åbenbart bønderne i landsbyen en god indtjening. De nøjedes da heller ikke med at formale deres egen havreproduktion (med håndkværn), men opkøbte til dette formål havre på de københavnske torve og ved skibene i havnen.

Endelig var der blegemændene i Sørup ved Esrom Sø og i Dragør, som levede af at vaske og blege tøj for kunderne i hovedstaden. København havde dog også en del blegemænd; deres arbejdspladser har givet navn til Blegdammen.

\section{Københavns ydre "Hinterland"}

Man kan imidlertid argumentere for, at hele Sjælland indgik i Københavns "hinterland" under enevælden. Skiftesager og indberetninger m.v. fra 1700-tallet viser i alt fald, at det ikke var unormalt, at bønder fra Syd- og Sydvestsjælland drog hele den lange vej til København for at sælge korn på hovedstadens torve. For kornpriserne var sædvanligvis meget højere i hovedstaden end $\mathrm{i}$ provinsen pga. den store efterspørgsel, og selvfølgelig havde København også et større og mere varieret udbud af varer. Nogle af de rejsende bønder passerede adskillige købstæder på deres vej til og fra København, og de lokale myndigheder i disse byer klagede ofte over denne trafik. Men at dømme efter indberetninger fra Køge og Roskilde, hhv. 1747 og 1775, har i alt fald nogle af købmændene i disse byer også tjent ganske godt på at beværte og indlogere de rejsende bønder under deres rejser. ${ }^{7}$

Derudover havde de sjællandske bønder kontakt til det københavnske marked gennem omrejsende kræmmere, som havde lov til at handle med bestemte varer. I 1721 fik beboerne i Valby således tilladelse til at drage omkring på Sjælland for at opkøbe fjerkræ og æg med henblik på salg i København. If $\varnothing$ lge et brev fra købmændene i Næstved i 1747 holdt de sig dog ikke til disse produkter, men opkøbte også huder, skind, gammel messing, kobber og smør. Og i en indberetning fra en Slangerup-købmand i 1775 får vi at vide, at Valby-prangerne ofte benyttede deres bes $\emptyset \mathrm{g}$ i København til at skaffe sig tobak, indigo og "alleslags Baandkram" hos hovedstadens fabrikanter for at afsætte disse varer til nordsjællandske bønder. ${ }^{8}$

\section{Linjer op til nutiden}

Selv om hovedstadsregionen har gennemgået en total forvandling i de sidste 200 år, kan der på flere måder trækkes linjer - måske ikke helt op til i dag, men så i alt fald til midten af 1900-tallet. Jeg vil belyse det med et par eksempler fra de seneste års boghøst.

Det første eksempel handler om fiskeleverancerne til København. I Kenn Tarbensens bog "Fisk til folket" kan man se, at Gammel Strand endnu indtil 1950'erne fungerede som hovedsalgssted for 
fisk, idet fiskerkonerne fra Skovshoved og Tårbæk her både solgte til engroshandlere og forbrugere. I slutningen af 1930'erne var Gammel Strand opdelt i 132 stadepladser, hvoraf fiskerkonerne havde de 67, mens resten var delt nogenlunde ligeligt mellem handlende ved landgangen, kommissionærer og ikke-faste torvehandlere. ${ }^{9}$

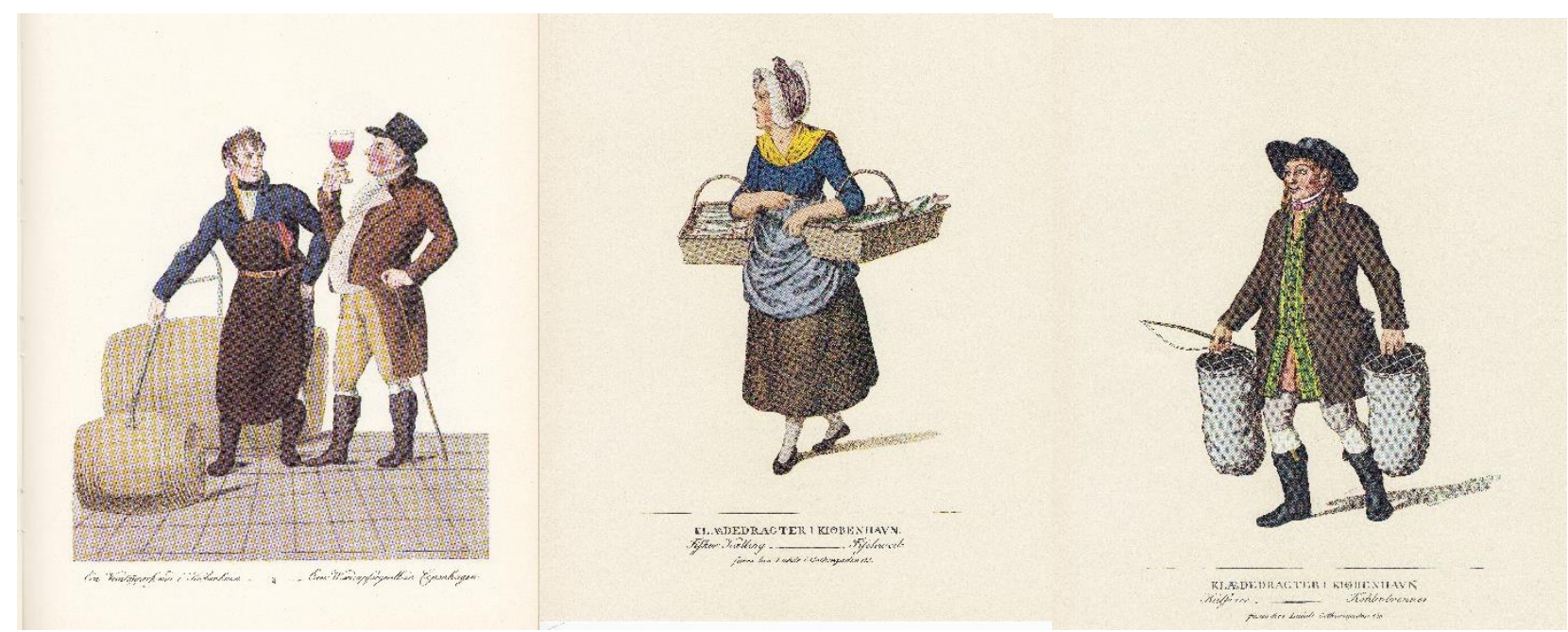

Fra venstre mod højre: En vintappersvend, en fiskerkalling og en kulsvier fra Lahdes billedsamling. (Købstadsmuseet Den Gamle By)

Det andet eksempel er hentet fra Bente Dahl Hansens store bidrag til bogen "Ballerup og Skovlunde", hvor to af omegnskommunernes klassiske erhvervsgrene, mælkeforsyning og gartneridrift, får en grundig behandling. I Skovlunde dannede nogle af beboerne omkring 1820 et såkaldt "flødelav", der påtog sig at transportere landsbyens overskudsproduktion af mælk og fløde ind til København, hvor disse varer blev solgt til private kunder. Især husmanden og skrædderen Lars Jensen lagde meget energi i dette arbejde, og han udviklede med tiden en virksomhed som mælkeforpagter (fast opkøber af nogle af naboernes produkter, typisk for et år ad gangen), der gik i arv til de næste tre generationer, hvorefter virksomheden udviklede sig til et mejeri. På dette tidspunkt var forpagternes kundekreds for længst blevet udvidet til også at omfatte bagere, mælkeudsalg og restaurationer m.m. i København. Adskillige andre beboere i Skovlunde fortsatte som selvstændige mælkeforpagtere i første halvdel af 1900-tallet, og den sidste af dem ophørte med dette arbejde i $1946 .^{10}$

Erhvervsgartneriet, som har stået stærkt i både Skovlunde og Ballerup, kom først i gang efter landbrugskrisen i 1870'erne, og den mest markante tilvækst fandt sted i 1910'erne og 20'erne. Alene i Skovlunde har der eksisteret mindst 15 gartnerier mellem 1920 og 1950. I tiden efter 1950 skete der en betydelig specialisering, samtidig med at flere og flere gartnerier blev afviklet, idet de jorder, som hidtil havde været anvendt til gartneri og landbrug, blev omdannet til beboelseskvarterer og erhvervsarealer. Gartnerivirksomheden i kommunen ophørte definitivt omkring $1970 .^{11}$ 


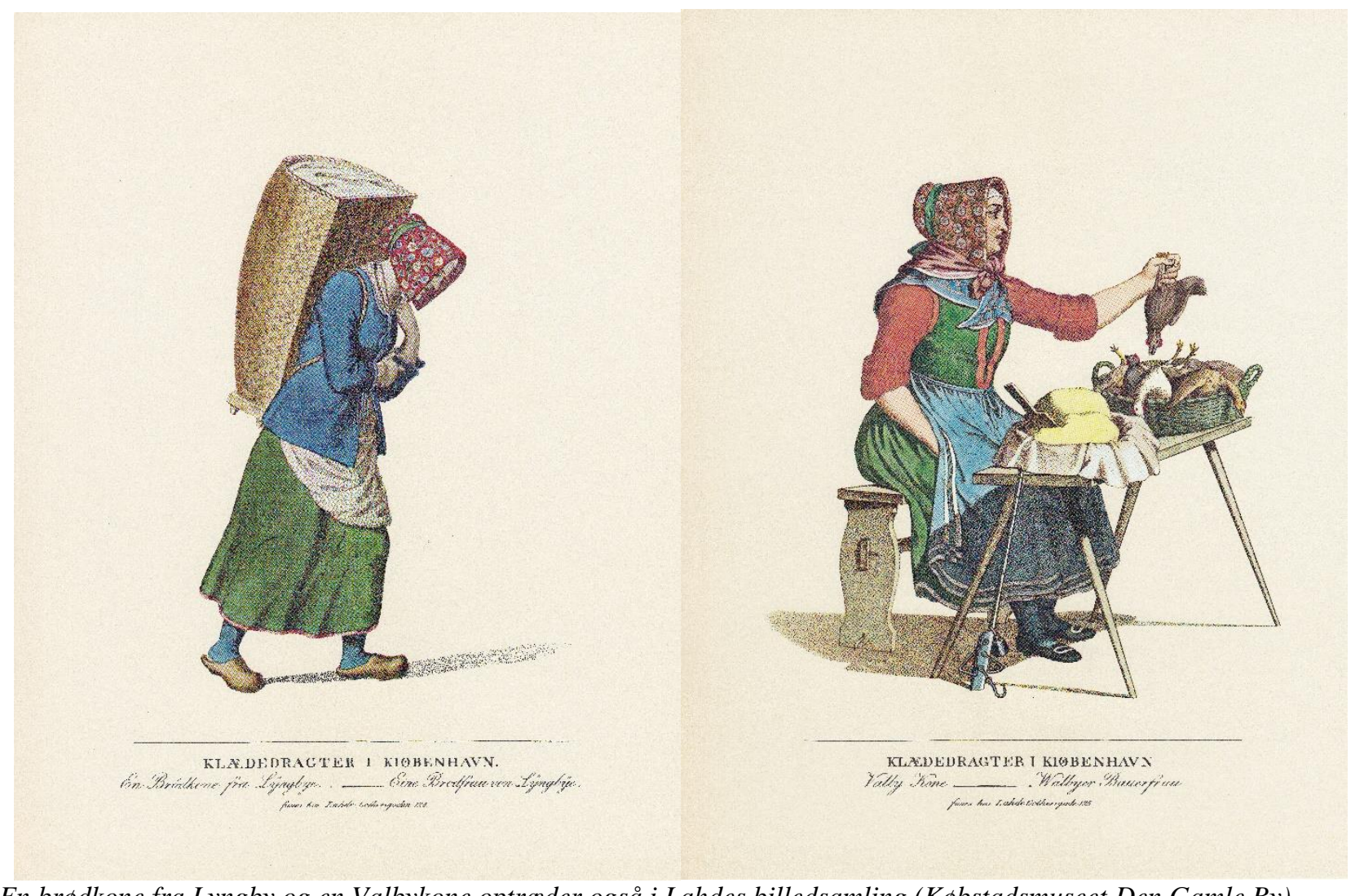

En brødkone fra Lyngby og en Valbykone optrceder også i Lahdes billedsamling (Købstadsmuseet Den Gamle By)

\section{Videre forskningsperspektiver}

Emnet "Københavns nære og fjerne opland" kan fortjene mange flere undersøgelser, end det har været tilfældet indtil nu. Da emnet indeholder et utal af facetter, kan det være hensigtsmæssigt at angribe det fra mange vinkler og med mange slags kilder.

I min ph.d.-afhandling om økonomiske relationer mellem by og land og mellem byerne indbyrdes på dele af Sjælland i 1700-tallet gjorde jeg således bl.a. brug af flere forskellige indberetninger og af de markedslister og markedspasprotokoller, som blev indført i 1775 til at holde styr på markedshandelen.

Men jeg havde særligt glæde af byfogedembedernes righoldige skiftemateriale, navnlig købmandsboernes korrespondance og debitorlister, dvs. lister over de kreditkunder, som endnu ikke havde betalt deres gæld, da købmanden døde eller gik fallit. En kortlægning af købmænds handelsnetværk på grundlag af sådanne kilder siger ganske meget om overlapninger mellem nabobyers handelsoplande og om styrkeforholdet mellem forskellige byer i samme region. ${ }^{12}$

\section{Summary}

German geographers and historians often distinguish between three concepts of catchment areas when writing about urban history before the industrialisation. The "Umland" up to 10-30 kilometres from the urban centre was the local area, from which people went to the weekly markets. The "Hinterland" stretching 50-60 kilometres away was the region that provided the city or town with new merchants, artisans and other citizens and with buyers at the fairs a few times each year. And 
the "Einflußbereich" was the more distant areas affected by the long distance trade of the city in question.

The concepts are suitable for an analysis of the economic relations between Copenhagen and other parts of Denmark before the industrialisation. The same applies to the so-called von Thünen zones, called after the German economist Johann Heinrich von Thünen who in the 1820s worked out the theory that a city or town is encircled by concentric production zones, when there is no real difference in the quality of the soil in the surrounding area, because the costs of transportation then settle what is most appropriate to grow at each place.

In the article "Københavnsbønder" Holger Rasmussen distinguished between three production zones when describing the catchment area of Copenhagen until the middle of the $19^{\text {th }}$ century. In the inner zone - you may call it the "Umland" - up to 10 kilometres from Copenhagen, the peasants used to provide the capital with milk and vegetables, bringing mash and manure back to the farms. In the next zone - 10-20 kilometres from Copenhagen - hay, straw and potatoes were important products for sale in the capital, while grain definitely was the main crop provided from more distant areas.

However, some local specialities existed in each of the zones. According to Rasmussen and his sources Hage and Sterm who made topographical works in the 1830s, several of them were due to natural resources. For instance, this applied to the supply of fish from Skovshoved, peat from Sengeløse and Kirke Værløse and wood charcoal from North Zealand. In contrast, there seems to be no special reason for the oatmeal production in Buddinge.

In addition to the analysis of Rasmussen, it should be remarked that really all parts of Zealand in a way belonged to the catchment area of Copenhagen, in any case in the $18^{\text {th }}$ century, when we know from several reports and probate cases that it was quite normal that peasants from Southern and Southwestern Zealand made trips to Copenhagen in order to sell grain at the markets in the capital, where it was possible for them to get a much higher price than in the towns in their neighbourhood. Of course, the tradesmen in the small towns disliked this traffic, but some of them in fact earned from offering lodgings to peasants on their journeys to and from Copenhagen.

In the end of the article, the author draws some lines up to the middle of $20^{\text {th }}$ century by describing the supplies of fish, milk and horticulture products to Copenhagen from the villages and towns Skovshoved, Ballerup and Skovlunde. After that there are some remarks on further studies in economic relations between Copenhagen and its surrounding areas and an appendix about the theory of von Thünen. 


\section{Appendix: von Thünens lokationsteori og senere anvendelse af teorien}

Johann Heinrich von Thünens lokationsteori er blevet betegnet som verdens første $\varnothing$ konomiske model, ${ }^{13}$ og da teorien har haft en del indflydelse på byhistorisk og geografisk forskning, kan det være på sin plads med en lidt nærmere omtale.

Von Thünens mål var at analysere de landbrugsmæssige produktionsstrukturer i en imaginær stat ("Der Isolierte Staat") med kun én meget stor by, som lå midt på en frugtbar slette, der ikke blev gennemstrømmet af floder eller kanaler. Desuden forudsatte von Thünen, at jordens bonitet overalt var den samme, og at befolkningen var fuldstændigt afskåret fra økonomisk samkvem med beboere uden for staten. ${ }^{14}$ Von Thünen argumenterede for, at byen under disse forudsætninger ville være omkranset af seks ringe, der hver havde sine afgrøder og produktionsformer.

De grundlæggende forudsætninger var, at bønderne på hvert sted handlede absolut rationelt i deres valg af afgrøder, og at de samlede omkostninger til jordrente, produktion og transport af de producerede varer ind til byen var afgørende for, hvad der blev dyrket på det enkelte sted. Von Thünen tog dog også hensyn til, at visse produkter var så letfordærvelige, at de nødvendigvis måtte produceres tæt ved byen for ikke at gå til under transporten.

Von Thünens værk indeholder flere generelle teser. Med Peter Halls ord lyder den ene således: "the general rule will be that the site nearest the market will be appropriated by that product which experiences the greatest cost reduction nearest the market, or in other words, the greatest cost increase away from the market". ${ }^{15}$ Bemærkningen er primært møntet på transportomkostningerne, der - i modsætning til jordlejen - voksede med afstanden til byen. Von Thünen understregede da også, at transportudgifterne var den mest afgørende faktor for lokaliseringen af landbruget i den ideelle stat. Han bemærkede således, at det kun kunne betale sig at producere varer, som var tunge og omfangsrige i forhold til deres værdi, i byens nærområde; ellers ville transportudgifterne blive alt for store.

Von Thünen hævdede ligeledes, at hvis to afgrøder havde lige store produktionsomkostninger pr. vareladning, ville det produkt, som havde det største omfangsmæssige udbytte pr. arealenhed, blive fremstillet nærmest ved byen, hvor transportomkostningerne kunne holdes nede på et lavt niveau. Da et stort udbytte ofte er forbundet med intensiv drift, har mange forskere været tilbøjelige til at fortolke von Thünens lokationsteori på den måde, at der eksisterer en direkte sammenhæng mellem dyrkningsintensitet og afstanden til markedet. Men dette er en forenkling, skriver Peter Hall, som dog samtidig medgiver, at produktionen i de inderste ringe ifølge von Thünen gennemgående var langt mere intensiv end arealanvendelsen i de mere perifere egne. Der er dog et par markante undtagelser fra denne regel. Eksempelvis argumenterede von Thünen for, at den næstinderste ring blev anvendt til skovbrug, selv om dette var en udpræget ekstensiv produktionsgren. Det skyldtes dels den store træproduktion pr. arealenhed, dels at det var meget besværligt og dyrt at transportere træ ad datidens landeveje - og der indgik jo ingen floder eller kanaler i von Thünens model. ${ }^{16}$

Med sit høje abstraktionsniveau har von Thünens teori været et let offer for kritik fra mange senere forskere, som har peget på, at produktionsmønstrene i et land påvirkes af mange andre faktorer end omkostninger til dyrkning og transport. Det drejer sig ikke blot om forskelle i jordbundens bonitet, infrastrukturen og befolkningstætheden i den pågældende region, men også om forskellige institutionelle faktorer (politiske, administrative og retslige forhold) såsom handelsregulerende bestemmelser og tariffer. 
Ikke desto mindre har von Thünens model vist sig brugbar ved beskrivelsen af oplandet for mange europæiske storbyer før industrialiseringen. Et godt eksempel er London, der bl.a. er blevet behandlet i Fernand Braudels storværk om civilisation, økonomi og kapitalisme. Her argumenterer Braudel for, at hele England med tiden blev inddraget i Londons forsørgelseszoner, men at der samtidig - også i områder ganske tæt ved hovedstaden - blev ved med at eksistere en masse traditionelle landbrug, som var totalt upåvirket af Londons efterspørgsel. I et synteseværk om det urbane Europa fra 1100 til 1700 bruger David Nicholas også London til at demonstrere von Thünens hovedpointe: Hvede og rug blev dyrket i en vis afstand fra storbyen, for priserne for disse produkter var tilstrækkeligt høje til at bære de store transportomkostninger. Derimod blev markerne nær ved London anvendt til dyrkning af den prisbillige havre. ${ }^{17}$

\section{Litteratur:}

Braudel, Fernand: Civilisation matérielle, economie et capitalisme, XVe-XVIIIe siècle, 1-3, 1979. Feldbæk, Ole: Danmarks historie, bind 4: Tiden 1730-1814, 1982.

Hage, Joh. Phil.: Bidrag til Kundskab om de danske Provindsers nuværende Tilstand i oeconomisk Henseende, 1839.

Hall, Peter (ed.): Von Thünen's Isolated State. An English Edition of Der Isolierte Staat ..., 1966. Hansen, Bente Dahl (red.): Ballerup og Skovlunde. Om dem der var her før os. Fra Landsby til Stationsby og Forstad, 2018.

Hanssen, Börje: Österlen. Allmoge, köpstafolk \& kultursammanhang vid slutet av 1700-talet i det sydöstra Skåne, 1952/1977.

Mikkelsen, Jørgen: Korn, købmænd og kreditter. Om kornhandel og kornpriser i Sydvestsjælland ca. 1740-1807, Fortid og Nutid, 1993, s. 178-213.

Mikkelsen, Jørgen: Købmandens kontaktflade - en regionalundersøgelse, Erhvervshistorisk Årbog 1994, s.106-145.

Mikkelsen, Jørgen: Sjællandske markeder 1775-1800, Historie 1994, s. 1-39.

Mikkelsen, Jørgen: "Handlingen i de Smaae Kiøbstæder bestaaer i dend bahre Credit". Økonomiske vilkår for de sjællandske købstæder i 1700-tallet - belyst gennem indberetninger, i: Knud Prange m.fl. (red.): Det store i det små, 1997, s. 119-143.

Mikkelsen, Jørgen: Urbanisering og bysystemer i Europa indtil ca. 1800, 2012.

Møller, Anders Monrad: Fra galeoth til galease. Studier i de kongerigske provinsers søfart i det 18. århundrede, 1981.

Nicholas, David: Urban Europe, 1100-1700, 2003.

Rasmussen, Holger: Københavnsbønder, Historiske meddelelser om København 1963, s. 75-98.

Reed, Michael: London and its Hinterland 1600-1800: the View from the Provines, i: Peter Clark \& Bernard Lepetit (eds.): Capital Cities and their Hinterlands in Early Modern Europe, 1996, s. 51-83. Scott, Tom \& Bob Scribner: Urban Networks, i: Bob Scribner (red.): Germany. A New Social and Economic History, vol. 1, 1996, s. 113-44.

Sterm, S.: Statistisk-Topographisk Beskrivelse over Kjøbenhavns Amt tildeels efter meddeelte Efterretninger fra vedkommende Embedsmænd og Ejere, 1836.

Tarbensen, Kenn: Fisk til folket, 2019.

\section{Noter:}

\footnotetext{
${ }^{1}$ Reed 1996, s. 57.

${ }^{2}$ Se fx Börje Hanssens detailanalyser fra Österlen (det østlige Skåne), hvor kildematerialet for det meste er fra tiden omkring 1800.

${ }^{3}$ Scott og Scribner 1996, s. 117.

${ }^{4}$ Se tabellen over alle danske byers befolkningstal i 1801/1803 i Feldbæk 1982, s. 125.

${ }^{5}$ Møller 1981.

${ }^{6}$ Rasmussen 1963, s. 86.
} 
${ }^{7}$ Mikkelsen 1997, s. 131-33.

${ }^{8}$ Mikkelsen 1997, s. 127.

${ }^{9}$ Tarbensen 2019, s. 40-41.

${ }^{10}$ Hansen 2018, s. 103-05 og 318-22.

${ }^{11}$ Hansen 2018, s. 313-18.

${ }^{12}$ Mikkelsen 1993, 1994a og 1994b.

${ }^{13}$ Hall 1966, s. xxi.

${ }^{14}$ Von Thünen søgte dog også at levere et omfattende empirisk grundlag for sine teser. Dokumentationen stammede fra hans gods i Mecklenburg, hvor han indsamlede regnskabsdata gennem en længere årrække. Man kan læse om dette i den lange introduktion i

Hall 1966, hvor Hall også har udgivet den del af forfatterskabet, inkl. efterladte papirer, som vedrører lokationsteorien.

${ }^{15}$ Hall 1966, s. xxxii.

${ }^{16}$ Hall 1966, s. xxi og xxxff.

${ }^{17}$ Braudel 1979, bd. II, kapitel 1; Nicholas 2003, s. 39. 